\title{
Predictors and Outcomes of Gastrointestinal Bleeding in Patients with Acute Myocardial Infarction
}

\author{
Tran-Thi-Khanh T1, Phan-Thi-Thuy $\mathbf{D}^{1}$ and Duong-Quy $\mathbf{S}^{2,3^{*}}$ \\ ${ }^{1}$ Pham Ngoc Thach University of Medicine, Hochiminh City, Vietnam \\ ${ }^{2}$ Penn State Medical College, USA \\ ${ }^{3}$ Department of Cardio-Respiratory Diseases, Cochin Hospital, Paris Descartes University, France
}

\begin{abstract}
Background and objectives: The risk of gastrointestinal bleeding in patients hospitalized with acute myocardial infarction is higher due to antiplatelet and anticoagulant agents along with revascularization. There are limited data about predictors and implications of gastrointestinal bleeding in acute myocardial infarction. Our research aims to investigate the incidence, predictors, clinical outcomes associated with gastrointestinal bleeding in patients with acute myocardial infarction.
\end{abstract}

Patients and methods: Cross sectional study was conducted. All patients diagnosed with acute myocardial infarction at Tam Duc Heart hospital from January 2013 to March 2017 were enrolled.

Results: A total of 643 patients with acute myocardial infarction were included ( $67.2 \pm 13.8$ years). Gastrointestinal bleeding occurred in $9.5 \%$. Multiple logistic regression analysis demonstrated that female (OR 2.21 ; Cl95\%: $1.02-$ 4.74; $p=0.044$ ), pneumonia (OR 2.76; Cl95\%: 1.25-6.08; $p=0.012$ ), impared renal function (OR 4.65; Cl95\%: $2.08-$ $10.4 ; p<0.001$ ) were independent predictors of gastrointestinal bleeding. Gastrointestinal bleeding was significantly associated with prolonged hospital stay ( 21.8 vs. 9.7 days; $p<0.01)$, increased the need of transfusion $(39.4 \%$ vs. $3.9 \% ; p<0.001)$, higher in-hospital mortality $(21.3 \%$ vs. $7.2 \%$; $p<0.01)$

Conclusion: The rate of gastrointestinal bleeding was $9.5 \%$. Female, pneumonia, impared renal function were independent predictors in patients with acute myocardial infartion.

Keywords: Acute myocardial infarction; Gastrointestinal bleeding

\section{Introduction}

Gastrointestinal (GI) bleeding is an important cause of morbidity and mortality in the population as well as in patients with cardiovascular disease [1]. Many studies show that GI bleeding in acute myocardial infarction (AMI) has a worse prognosis, even in mild cases. In addition, the treatment of these patients including the combination of antiplatelet agents, thrombolysis, anticoagulant therapy increases the risk of bleeding, especially GI bleeding [1]. GI bleeding prolongs hospital stay, higher in-hospital mortality and 6-month mortality [24]. Despite advanced in diagnosis and treatment, mortality after GI bleeding is still around 10\% during the last half decade and higher inhospital mortality in severe patients [3].

At present, cardiovascular and GI physicians in our country have few reliable data on the frequency of GI bleeding, optimal treatment strategy and prognosis of GI bleeding in patients with AMI. Therefore, we found it necessary to perform this study to determine the risk factors and effect of GI bleeding in patients with AMI with three following objectives: to describe the clinical characteristics, laboratory test and treatment of GI bleeding in patients with AMI; to identify predictors of GI bleeding in patients with AMI; to determine and compare the rates of outcomes in patients with and without GI bleeding in patients with AMI

\section{Methods}

\section{Study design}

It was a prospective cohort study.

\section{Inclusion criteria}

All patients diagnosed with acute myocardial infarction at Tam
Duc Heart hospital from January 2013 to March 2017 were enrolled in this study.

\section{Exclusion criteria}

Patients with uncompleted data were excluded from the study.

\section{Definition}

Acute myocardial infarction: Detection of a rise and/or fall of cardiac biomarker values [preferably cardiac troponin (cTn)] with at least one value above $99^{\text {th }}$ percentile upper reference limit and with at least one of the following: Symtoms of ischaemia; New or presumed new significant ST-segment-T-waves (ST-T) changes or new left bundle branch block; Development of pathological Q waves in the ECG; Imaging evidence of new loss of viable myocardium or new regional wall motion abnormality; Identification of an intracoronary thrombus by angiography [5].

Gastrointestinal bleeding: Overt GI bleeding: at least one of three following symtoms:

- Hematemesis or blood in nasogastric tube

*Corresponding author: Sy Duong-Quy, MD, PhD, Department of CardioRespiratory Diseases, Cochin Hospital, Paris Descartes University, France, Tel: +0033679193377; E-mail: sduongquy.jfvp@gmail.com

Received August 16, 2018; Accepted August 24, 2018; Published August 31, 2018

Citation: Tran-Thi-Khanh T, Phan-Thi-Thuy D, Duong-Quy S (2018) Predictors and Outcomes of Gastrointestinal Bleeding in Patients with Acute Myocardial Infarction. J Vasc Med Surg 6: 368. doi: 10.4172/2329-6925.1000368

Copyright: (c) 2018 Tran-Thi-Khanh T, et al. This is an open-access article distributed under the terms of the Creative Commons Attribution License, which permits unrestricted use, distribution, and reproduction in any medium, provided the original author and source are credited. 
Citation: Tran-Thi-Khanh T, Phan-Thi-Thuy D, Duong-Quy S (2018) Predictors and Outcomes of Gastrointestinal Bleeding in Patients with Acute Myocardial Infarction. J Vasc Med Surg 6: 368. doi: 10.4172/2329-6925.1000368

Page 2 of 5

- Hematochezia

- Melena

Occult GI bleeding:

- Positive fecal occult blood (FOB) test

Hemoglobin drop of more than or equal to $2 \mathrm{~g} / \mathrm{dL}$ without an identifiable extraintestinal sourse [6]

Anemia at admission: According to WHO (World Health Organization), anemia occurs when $\mathrm{Hb}<13 \mathrm{~g} / \mathrm{dL}$ for men and $\mathrm{Hb}<12$ $\mathrm{g} / \mathrm{dL}$ for women.

Death: Including death and serious cases considered as death.

\section{Statistical analysis}

Statistics were performed with SPSS version 22.0 (Chicago; USA). The $\mathrm{P}$ value of $<0.05$ was considered significant for all tests. The $\chi 2$ test to compare two ratios, t-test to compare two means. Non-standard deviation variable is described by median and interquartile range (IQR) (25\%-75\%). Significant clinical factors associated with GI bleeding were identified by univariable logistic regression analysis and then included in the multivariate logistic regression model with $\mathrm{p}<0.25$.

\section{Results}

A total of 643 patients with AMI admitted to Tam Duc Heart hospital from January 2013 to March 2017 were included in the present study.

\section{Study population}

The anthropometric and clinical features of study subjects were presented in Table 1 . The mean age was $67.2 \pm 13.8$ years old with $68.7 \%$ of male and $31.3 \%$ of female.

\begin{tabular}{|l|c|}
\hline & Frequency (\%) \\
\hline N & 643 \\
\hline Sex & $67.2 \pm 13.8$ \\
\hline Male & $442(68.7 \%)$ \\
\hline Female & $201(31.3 \%)$ \\
\hline GI history & \\
\hline Prior epigastric pain & $13(2.0 \%)$ \\
\hline Prior peptic ulcer disease & $54(8.4 \%)$ \\
\hline Prior GI bleeding & $8(1.2 \%)$ \\
\hline NSAIDs medication & $3(0.5 \%)$ \\
\hline Glucocorticoids medication & $3(0.5 \%)$ \\
\hline Medical history & $48(7.5 \%)$ \\
\hline Prior MI & $46(7.2 \%)$ \\
\hline Prior PCI & $9(1.4 \%)$ \\
\hline Prior CABG & $13(2.0 \%)$ \\
\hline Prior heart failure & $63(9.8 \%)$ \\
\hline Chronic renal failure & $17(2.6 \%)$ \\
\hline Prior COPD & $27(4.2 \%)$ \\
\hline Stroke & $10(1.6 \%)$ \\
\hline Asthma & $434(67.5 \%)$ \\
\hline Atherosclerosis factors & $199(30.9 \%)$ \\
\hline Hypertension & $254(39.5 \%)$ \\
\hline Diabetes & \\
\hline Dyslipidemia & \\
\hline & \\
\hline & \\
\hline & \\
\hline
\end{tabular}

\begin{tabular}{|c|c|}
\hline Smoking & $250(38.9 \%)$ \\
\hline \multicolumn{2}{|l|}{ Clinical characteristics } \\
\hline Length of hospital stay. mean & $10.93 \pm 12$ \\
\hline Admission heart rate (bpm) & $81.6 \pm 22.5$ \\
\hline $\begin{array}{l}\text { Admission systolic blood pressure } \\
(\mathrm{mmHg})\end{array}$ & $128.2 \pm 30.2$ \\
\hline $\begin{array}{l}\text { Admission diastolic blood pressure } \\
(\mathrm{mmHg})\end{array}$ & $74.6 \pm 17.7$ \\
\hline Killip III, IV at admission & $114(17.7 \%)$ \\
\hline Mechanical ventilator & $77(12.0 \%)$ \\
\hline Vasopressors use & $127(19.8 \%)$ \\
\hline Intra-aortic balloon pump & $53(8.2 \%)$ \\
\hline Pneumonia & $174(27.1 \%)$ \\
\hline Anemia at admission & $214(33.3 \%)$ \\
\hline ST-segment elevation at admission & $277(43.1 \%)$ \\
\hline GI bleeding & $61(9.5 \%)$ \\
\hline Upper GI bleeding & $16(2.5 \%)$ \\
\hline Lower GI bleeding & $3(0.5 \%)$ \\
\hline Occult GI bleeding & $42(6.5 \%)$ \\
\hline \multicolumn{2}{|l|}{ Treatment strategy } \\
\hline Revascularization & $493(76.7 \%)$ \\
\hline Medical management & $150(23.3 \%)$ \\
\hline Endoscopy & $9(1.4 \%)$ \\
\hline PPI drug use & $615(95.6 \%)$ \\
\hline \multicolumn{2}{|l|}{ Outcome } \\
\hline Death & $55(8.6 \%)$ \\
\hline Survival & $(91.4 \%)$ \\
\hline
\end{tabular}

Table 1: Anthropometric and clinical characteristics of study subjects.

Note: NSAID: Non-Steroid Anti-Inflammatory Drugs; MI: Myocardial Infraction; PCI: Percutaneous Coronary Intervention; CABG: Coronary Artery Bypass Graft COPD: Chronic Obstructive Pulmonary Disease; GI: Gastrointestinal; PPI: Proton Pump Inhibitors.

\section{Clinical features, laboratory test and treatment in AMI patients with and without gastrointestinal bleeding}

All the clinical and biological data of AMI patients with and without gastrointestinal bleeding were presented in Table 2 .

\section{Treatment of gastrointestinal bleeding during hospitalization}

All of the AMI patients with overt upper GI bleeding were controlled with high doses PPI (proton pump inhibitors) intravenously for 72 hours and switched to oral route. Occult GI bleeding were treated with intravenous or oral PPI. Four cases of GI bleeding were identified as acquired coagulation disorders due to multiple organ failure and/ or thrombolytic therapy. These cases were supplemented with fresh frozen plasma, cryoprecipitated, and platelet concentrate.

In GI bleeding group, the time of event occurs on the second day with overt GI bleeding (IQR, 1-5) and upper GI bleeding (IQR, 1-7) and the third day with lower GI bleeding (IQR, 1-5). There were 9 (14.8\%) patients underwent endoscopy (Table 3) and none of them had complications at the time of endoscopy (arrthymia, hypotension, respiratory failure). The mean hemoglobin dropped from $11.0 \pm 2.6 \mathrm{~g} /$ dL to $9.4 \pm 2.0 \mathrm{~g} / \mathrm{dL}$. Most of patients didn't have ST-segment elevation at admission $(60.7 \%)$. The need for transfusion is 24 cases $(39.4 \%)$ The number for pack red blood cell needed was one unit on average. $8(13.1 \%)$ patients had to stop anticoagulant therapy. Only one case underwent emergency endoscopy $(<12$ hours). Almost cases were performed endoscopy after cardiovascular stablization. There wasn't recurrent GI bleeding during hospitalization. PPI was used in almost cases $(98.4 \%)$. 
Citation: Tran-Thi-Khanh T, Phan-Thi-Thuy D, Duong-Quy S (2018) Predictors and Outcomes of Gastrointestinal Bleeding in Patients with Acute Myocardial Infarction. J Vasc Med Surg 6: 368. doi: 10.4172/2329-6925.1000368

Page 3 of 5

\begin{tabular}{|c|c|c|c|}
\hline \multirow[b]{2}{*}{ Characteristics } & \multicolumn{2}{|c|}{ Patients } & \multirow[b]{2}{*}{$P$ value } \\
\hline & $\begin{array}{c}\text { With GI } \\
\text { bleeding } \\
n=61\end{array}$ & $\begin{array}{c}\text { Without GI } \\
\text { bleeding } \\
n=582\end{array}$ & \\
\hline Age, yrs & $76.3 \pm 10.4$ & $66.2 \pm 13.7$ & $p<0.001$ \\
\hline Female sex & $35(57.4 \%)$ & $166(28.5 \%)$ & $p<0.001$ \\
\hline \multicolumn{4}{|l|}{ Medical history } \\
\hline Prior epigastric pain & $3(4.9 \%)$ & $10(1.7 \%)$ & $p=0.091$ \\
\hline Prior peptic ulcer disease & $7(11.5 \%)$ & $47(8.1 \%)$ & $p=0.362$ \\
\hline Prior GI bleeding & $3(4.9 \%)$ & $5(0.9 \%)$ & $p=0.007$ \\
\hline NSAIDs medication & $0(0 \%)$ & $3(0.5 \%)$ & $p=0.574$ \\
\hline Glucocorticoids medication & $0(0 \%)$ & $3(0.5 \%)$ & $p=0.574$ \\
\hline Prior MI & $3(4.9 \%)$ & $45(7.7 \%)$ & $p=0.426$ \\
\hline Prior $\mathrm{PCl}$ & $7(11.5 \%)$ & $39(6.7 \%)$ & $p=0.169$ \\
\hline Prior CABG & $0(0 \%)$ & $9(1.5 \%)$ & $p=0.328$ \\
\hline Prior heart failure & $4(6.6 \%)$ & $9(1.5 \%)$ & $p=0.008$ \\
\hline Chronic renal failure & $17(27.9 \%)$ & $46(7.9 \%)$ & $p<0.001$ \\
\hline Prior COPD & $3(4.9 \%)$ & $14(2.4 \%)$ & $p=0.245$ \\
\hline Stroke & $5(8,2 \%)$ & $22(3,8 \%)$ & $p=0,102$ \\
\hline Asthma & $0(0 \%)$ & $10(1,7 \%)$ & $p=0,302$ \\
\hline Hypertension & $51(83,6 \%)$ & $383(65.8 \%)$ & $p=0.005$ \\
\hline Diabetes & $30(49.2 \%)$ & $169(28.9 \%)$ & $p=0.001$ \\
\hline Dyslipidemia & $14(23 \%)$ & $236(40.6 \%)$ & $p=0.007$ \\
\hline Smoking & $23(37.7 \%)$ & $231(39.7 \%)$ & $p=0.76$ \\
\hline Admission heart rate (bpm) & $91.1 \pm 27.5$ & $80.5 \pm 21.7$ & $p=0.005$ \\
\hline $\begin{array}{l}\text { Admission systolic blood pressure } \\
(\mathrm{mmHg})\end{array}$ & $124.9 \pm 35.6$ & $128.5 \pm 29.5$ & $p=0.373$ \\
\hline $\begin{array}{l}\text { Admission diastolic blood pressure } \\
(\mathrm{mmHg})\end{array}$ & $69.2 \pm 19.9$ & $75.1 \pm 17.3$ & $p=0.013$ \\
\hline Killip III, IV at admission & $23(37.7 \%)$ & $91(15.6 \%)$ & $\mathrm{p}<0.001$ \\
\hline Pneumonia & $43(70.5 \%)$ & $131(22.5 \%)$ & $\mathrm{p}<0.001$ \\
\hline Anemia at admission & $37(60.7 \%)$ & $177(30.4 \%)$ & $\mathrm{p}<0.001$ \\
\hline Vasopressorsssors use & $31(50.8 \%)$ & $96(16.5 \%)$ & $\mathrm{p}<0.001$ \\
\hline Mechanical ventilator & $26(42.6 \%)$ & $51(8.8 \%)$ & $\mathrm{p}<0.001$ \\
\hline Intra-aortic balloon pump & $13(21.3 \%)$ & $40(6.9 \%)$ & $\mathrm{p}<0.001$ \\
\hline ST-segment elevation at admission & $24(39.3 \%)$ & $253(43.5 \%)$ & $p=0.536$ \\
\hline LVEF $<40 \%$ at admission & $19(31.1 \%)$ & $107(18.4 \%)$ & $p=0.017$ \\
\hline $\begin{array}{l}\text { Troponin } \mathrm{T}_{\text {hs }} \text { peak. mean (SD), pg/ } \\
\mathrm{mL}\end{array}$ & $\begin{array}{l}4085.0 \pm \\
7906.7\end{array}$ & $\begin{array}{l}4142.8 \pm \\
9416.9\end{array}$ & $p=0.963$ \\
\hline $\mathrm{Hb}$, mean (SD), g/dL & $11.0 \pm 2.6$ & $13.4 \pm 2.0$ & $\mathrm{p}<0.001$ \\
\hline Platelet, mean (SD), Giga/L & $243.8 \pm 103.5$ & $241.4 \pm 80.6$ & $p=0.862$ \\
\hline PT, mean (SD), \% & $85.3 \pm 21.2$ & $93.0 \pm 12.9$ & $p=0.007$ \\
\hline aPTT, mean (SD), s & $34.2 \pm 14.5$ & $32.5 \pm 13.5$ & $p=0.367$ \\
\hline Fibrinogen, mean (SD), g/L & $4.1 \pm 1.7$ & $3.8 \pm 1.9$ & $p=0.189$ \\
\hline Cholesterol, mean (SD), mmol/L & $4.0 \pm 1.4$ & $4.8 \pm 1.4$ & $p<0.001$ \\
\hline Triglycerid, mean (SD), mmol/L & $2.0 \pm 1.2$ & $2.3 \pm 1.8$ & $p=0.165$ \\
\hline $\mathrm{HDL}$, mean (SD), mmol/L & $1.0 \pm 0.4$ & $1.1 \pm 0.4$ & $p=0.122$ \\
\hline LDL, mean (SD), mmol/L & $2.6 \pm 1.1$ & $3.1 \pm 1.8$ & $p=0.025$ \\
\hline AST, mean (SD), U/L & $138.0 \pm 370.4$ & $\begin{array}{c}100.6 \pm \\
193.8\end{array}$ & $p=0.441$ \\
\hline $\mathrm{ALT}$, mean (SD), U/L & $99.0 \pm 271.7$ & $60 \pm 119.6$ & $p=0.272$ \\
\hline Creatinine, mean (SD), mg/dL & $145.9 \pm 79.0$ & $107.9 \pm 74.2$ & $p=0.001$ \\
\hline MDRD, mean (SD), ml/min/1,73m² & $49.4 \pm 27.2$ & $70.1 \pm 23.3$ & $p<0.001$ \\
\hline
\end{tabular}

Table 2: Clinical and biological data of AMI patients with and without gastrointestinal bleeding.

Note: NSAID: Non-Steroid Anti-Inflammatory Drugs; MI: Myocardial Infraction PCl: Percutaneous Coronary Intervention; CABG: Coronary Artery Bypass Graft; COPD: Chronic Obstructive Pulmonary Disease; GI: Gastrointestinal; LVEF: Left Ventricular Ejection Fraction; MDRD: Modification of Diet in Renal Disease.

\begin{tabular}{|l|l|c|}
\hline & \multicolumn{1}{|c|}{ Endoscopy } & Number \\
\hline Esophagogastroduodenoscopy & $\begin{array}{l}\text { Gastric and duodenal ulcer } \\
\text { Forest III } \\
\text { Large lesser curvature gastric } \\
\text { ulcer suspected cancer }\end{array}$ & 2 \\
\hline & Erosive fundus & 1 \\
\hline Glexible sigmoidoscopy & Gastritis with multi-polyp & 1 \\
\hline Colonoscopy & Gastritis & 2 \\
\hline & Multi sigmoid ulcer & 1 \\
\hline
\end{tabular}

Table 3: Characteristics of patients with GI bleeding in endoscopy.

\section{Predictors of GI bleeding in patients with AMI}

In our study, we assessed the risk factors of GI bleeding in AMI patients by univariable logistic regression analysis and noted that all of the following conditions were correlated with GI bleeding $(\mathrm{p}<0.25)$ including age $\geq 70$ years old, female, history of GI bleeding or heart failure or chronic renal failure or hypertension or diabetes mellitus or no smoking, at admission with heart rate $\geq 100$ beat per minute, diastolic blood pressure $<60 \mathrm{mmHg}$, anemia, Killip III, $\mathrm{IV}$, thrombocytopenia $<100000 / \mathrm{mm}^{3}, \mathrm{PT}<70 \mathrm{~s}$, renal failure with MDRD (Modification of Diet in Renal Disease) $<60 \mathrm{ml} / \mathrm{ph} / 1.73$ $\mathrm{m}^{2}$, left ventricular ejection fraction on echocardiography $<40 \%$ and during hospital stay with mechanical ventilation, vasopressors use, IABP (intra aortic balloon pump), pneumonia. However, in multivariate logistic regression analysis, only females, pneumonia and impaired renal function were independent risk factors of GI bleeding (Figure 1).

\section{Outcomes of study patients}

In our present study, the group of AMI patients with GI bleeding had higher length of hospital stay than in group without GI bleeding ( 21.84 vs 9.79 days) $(\mathrm{p}<0.01)$. The rate of AMI patients with GI bleeding needed tranfusion higher than in group without GI bleeding $(39.4 \%$ vs $3.9 \%)(\mathrm{p}<0.001)$.

The overall in-hospital mortality rate was $8.6 \%$. The percentage of mortality in AMI patients with and without GI bleeding was $21.3 \%, 7.2 \%$, respectively $(\mathrm{p}<0.001)$. AMI patients with GI bleeding was significantly increased in-hospital mortality with $\mathrm{OR}=3.48$ (95\% C.I. 1.75-6.93, p<0.001) compared to AMI patients without GI bleeding. We identified 5 independent predictors of in-hospital mortality in AMI patients when analysing multivariable logistic regression including diabetes mellitus, at admission with systolic blood pressure $<90 \mathrm{mmHg}$; Killip III, IV; impaired renal failure, LVEF $<40 \%$ (Figure 2).

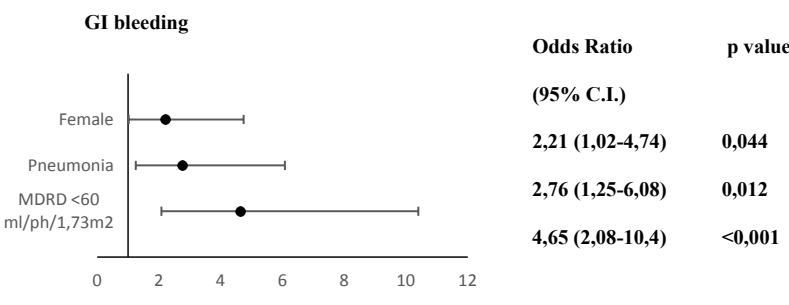

Figure 1: Multivariable predictors of GI bleeding in patients with AMI. 


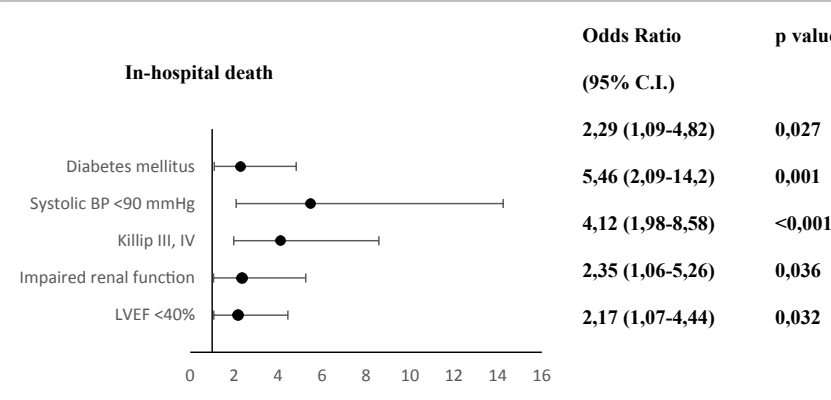

Figure 2: Multivariable predictors of in-hospital death in patients with AMI.

\section{Discussion}

The mean age of patients in this study was $67.2 \pm 13.8$. The ratio on distribution of gender male:female was $2.2: 1$ and this result was compatible to previous studies on AMI. GI bleeding was observed in 9.5\%, in which overt GI bleeding was 3.0\% and occult GI bleeding was $6.5 \%$. The proportion of GI bleeding reported in the previous studies about $1-9 \%$ in patients with AMI [2-4]. The rate of overt GI bleeding in AMI patients according to Guo was 2\% [7], $\mathrm{Ng}$ was 2.7\% [4] and $\mathrm{Al}-$ Mallah was 3.0\% [3], which was similar to ours. Occult GI bleeding in our study accounted for the proportion of $6.5 \%$ higher than $2.6 \% \mathrm{Ng}$ et al. [4], which may be due to different sampling methods. In addition, upper and lower GI bleeding were observed respectively on the second and third days. Therefore, we found that it is necessary to monitor hematocrit and hemoglobin $(\mathrm{Hb})$ during treatment AMI on some high risks patients, especially in 7 first days.

In our study, the average age $(\mathrm{p}<0.001)$, female gender, history of GI bleeding or heart failure or chronic renal failure or hypertension or diabetes $(\mathrm{p}<0.05)$, tachycardia, low diastolic pressure, Killip III or $\mathrm{IV}$, anemia, $\mathrm{EF}<40 \%$ at admission, pneumonia, mechanical ventilation, vasopressors use, IABP $(\mathrm{p}<0.05)$ in GI bleeding group was higher than that in non GI bleeding group. Our results were not different compared to others [2-4,6-10]. On biochemistry, mean values of $\mathrm{Hb}$, PT, Cholesterol, LDL, MDRD at admission in GI bleeding group were significantly lower than that in non GI bleeding group $(\mathrm{p}<0.05)$. Hypotension resulting from cardiac shock with hypoperfusion to gastric and intestinal mucosa will lead to mucosal erosions, increasing the likelihood of ulcers developing and subsequent bleeding [6].

The management of GI bleeding in AMI patients still has many difficulties. Anticoagulation and antiplatelet agents in the treatment of AMI patients increase risk of GI bleeding and, after that, GI bleeding can cause re-infarction. Previous studies showed that early endoscopy reduced re-bleeding and mortality $[11,12]$. In our study, only $14.8 \%$ patients were performed endoscopy. Most of them had gastritic and peptic ulcer disease on endoscopy. We found that it was necessary to resuscitation before endoscopy. Patients should be underwent diagnostic and therapeutic endoscopy within 24 hours, preferably after resuscitation and stable hemodynamic conditions.

In our study, multivariable analysis comfirmed the association of female, pneumonia and impaired renal function with GI bleeding. Predictors of GI bleeding were age $\geq 75$ years ole, female, previous AMI, pneumonia, anemia at admission in the Guo's study [7] and previous GI bleeding, impaired renal failure with $\mathrm{MDRD}<60 \mathrm{ml} / \mathrm{ph} / 1,73 \mathrm{~m}^{2}$, Killip IV at admission in the Chua's study [6]. Additionally, some of other risk factors composed of aspirin and/or NSAIDs use at home, organ dysfunction, dual antiplatelet agents and anticoagulant use $[7,9,10,13]$.
Overall, the predictors of GI bleeding in AMI patients in our research were as the same as others. Our study found that female increased GI bleeding in AMI patients. Biological differences in platelet function and vascular reactivity, with different "response" to antithrombotic treatments account for most of these sex-based differences. In addition, gender-related difference associated with antithrombotic treatment due to lower body mass and renal function in women than men [14] Consequently, the treatment related to anticoagulation should be in caution and pay attention to the dose on female patients due to their low body mass and high risk of bleeding.

Impaired renal failure was independent predictor of GI bleeding in our study. The percentage of acquired renal failure at the all stages in patients with acute coronary syndrome is about $30-40 \%$, which make the prognosis severely and higher risk of bleeding. The patients with acute coronary syndrome had renal failure often have a high risk of bleeding because of anticoagulants overdose. Furthermore, renal dysfunction, which has been related to impairment of platelet aggregation and alteration of platelets' interaction with vessel wall, was also a risk factor for gastrointestinal bleeding [6]. Therefore, we realized that it is necessary to estimate glomerular filtration rates as soon as patients admitted to the hospital. Some of patients known to have renal failure or risk of renal impairment should avoid use some specific anticoagulants or need to reduce the dose reasonably.

Previous studies reported that pneumonia increased risk of GI bleeding [3,7]. The organ dysfunction was also one risk factor of GI bleeding. This may be a stress factor of gastro-duodenal ulceration. GI bleeding tends to occur in patients with underlying conditions such as anemia, renal failure and cardiac shock [10]. The mean hospital stay in this study showed that the AMI patients with GI bleeding had higher than those without GI bleeding, possibly due to prolonged GI bleeding treatment and antithrombotic therapy. In previous studies, GI bleeding prolonged hospital stay $[6,9]$ and increased length of intensive care unit stay [7].

The overall mortality rate in the present study was $8.6 \%$ and inhospital mortality in GI bleeding group was higher than in non GI bleeding group. AMI patients with GI bleeding group was 3.48 fold increased hospital mortality compared to AMI patients without GI bleeding group (95\% CI; 1.75-6.93; $\mathrm{p}<0.001)$. Some reports showed the higher mortality rate of GI bleeding in AMI patients, by $3-10 \%$ $[2,3,6,9]$. Our study found that most patients with GI bleeding were treated with high doses of PPI, transfusion and endoscopy when stablizing cardiovascular condition. The univariable analysis showed the correlation between GI bleeding and in-hospital mortality, but this correlation seemed disappeared during multivariable analysis. Therefore, the cause of death in AMI patients was not due to GI bleeding but mainly due to cardiovascular events. Kirrkert reported that GI bleeding was not significantly associated with subsequent adverse major cardiac events, cardiac and all-cause mortality, recurrent MI, stroke or stent thrombosis [10]. The mortality in AMI patients was increased with hypotension, acute pulmonary oedema, cardiac shock, renal failure, decreased left ventricular function.

\section{Conclusion}

The rate of GI bleeding in AMI patients was 9.5\%. Female, pneumonia, impaired renal failure with $\mathrm{MDRD}<60 \mathrm{ml} / \mathrm{ph} / 1,73 \mathrm{~m}^{2}$ were independent predictors in AMI patients with GI bleeding. Gi bleeding prolonged hospital stay, increased the need of transfusion and not a major risk of in-hospital mortality. 
Citation: Tran-Thi-Khanh T, Phan-Thi-Thuy D, Duong-Quy S (2018) Predictors and Outcomes of Gastrointestinal Bleeding in Patients with Acute Myocardial Infarction. J Vasc Med Surg 6: 368. doi: 10.4172/2329-6925.1000368

Page 5 of 5

\section{References}

1. Moukarbel GV, Signorovitch JE, Pfeffer MA, McMurray JJ, White HD, et al. (2009) Gastrointestinal bleeding in high risk survivors of myocardial infarction: the VALIANT Trial. Eur Heart J 30: 2226-2232.

2. Abbas AE, Brodie B, Dixon S, Marsalese D, Brewington S, et al. (2005) Incidence and prognostic impact of gastrointestinal bleeding after percutaneous coronary intervention for acute myocardial infarction. Am J Cardiol 96: 173-176.

3. Al-Mallah M, Bazari RN, Jankowski M, Hudson MP (2007) Predictors and outcomes associated with gastrointestinal bleeding in patients with acute coronary syndromes. J Thromb Thrombolysis 23: 51-55.

4. Ng FH, Wong SY, Lam KF, Chang CM, Lau YK, et al. (2008) Gastrointestinal bleeding in patients receiving a combination of aspirin, clopidogrel, and enoxaparin in acute coronary syndrome. Am J Gastroenterol 103: 865-871.

5. Thygesen K, Alpert JS, Jaffe AS, Simoons ML, Chaitman BR, et al. (2012) Third universal definition of myocardial infarction. Circulation 126: 2020-2035.

6. Chua SK, Liao CS, Hung HF, Cheng JJ, Chiu CZ, et al. (2011) Gastrointestina bleeding and outcomes after percutaneous coronary intervention for STsegment elevation myocardial infarction. Am J Crit Care 20: 218-225.

7. Guo X, Zhao Y, Li J, Wang D, Xue Q, et al. (2008) Overt gastrointestinal bleeding in patients with acute myocardial infarction: retrospective analysis of risks and outcomes. J Geriatr Cardiol 5: 195-198.

8. Cuschieri JR, Drawz P, Falck-Ytter Y, Wong RC (2014) Risk factors for acute gastrointestinal bleeding following myocardial infarction in veteran patients who are prescribed clopidogrel. J Dig Dis 15: 195-201.

9. Ergelen M, Uyarel H, Soylu O, Ayhan E, Ciçek G, et al. (2010) Gastrointestina bleeding in patients undergoing primary angioplasty for acute myocardial infarction: incidence, risk factors and prognosis. Turk Kardiyol Dern Ars 38 101-106.

10. Kikkert WJ, Hassell ME, Delewi R, Van Der Laan MH, Baan J, et al. (2015) Predictors and prognostic consequence of gastrointestinal bleeding in patients with ST-segment elevation myocardial infarction. Int J Cardiol 184: 128-134.

11. Cena M, Gomez J, Alyousef T, Trohman RG, Pierko K, et al. (2012) Safety of endoscopic procedures after acute myocardial infarction: A systematic review. Cardiol J 19: 447-452.

12. Marcus WSC, Yong G, Bulsara MK, Rankin J, Forbes GM (2007) Predictive and protective factors associated with upper gastrointestinal bleeding after percutaneous coronary intervention: A Case-Control Study. Am J Gastroenterol 102: $2411-2416$

13. Barada K, Karrowni W, Abdallah M, Shamseddeen W, Sharara Al, et al. (2008) Upper gastrointestinal bleeding in patients with acute coronary syndromes: clinical predictors and prophylactic role of proton pump inhibitors. J Clin Gastroenterol 42: 368-372.

14. Marcucci R, Cioni G, Giusti B, Fatini C, Rossi L, et al. (2014) Gender and anti-thrombotic therapy: from biology to clinical implications. J Cardiovas Transl Res 7: 72-81. 